\title{
Importance of renal dysfunction in the mortality of acute coronary syndrome patients
}

\author{
Maria Eduarda Seabra Halmeira ${ }^{1}$, Nathalia R. Sousa ${ }^{2}$, Camila N. Santana ${ }^{3}$, Mário S. Rocha ${ }^{3}$
}

\footnotetext{
1) Bahiana School of Medicine and Public Health, Salvador, Bahia, Brazil;

2) Pernambuco Federal University, Fortaleza, Pernambuco, Brazil;

3) Portuguese Hospital, Salvador, Bahia, Brazil
}

\begin{abstract}
Background: Ischemic heart disease is an important death cause in Brazil. The Acute Coronary Syndrome is a subset of signs and symptoms which represents an acute complication of ischemic heart disease. Many of these patients have common risk factors, including renal dysfunction. The analysis of the importance of this commitment in the event of outcomes is still little explored in our midst.

Objective: To study the associantion betweent renal dysfunction and the occurrence of deaths in patients with Acute Coronary Syndrome, Methods: This is a analytical study, with patients admitted to the Coronary Care Unit of a Tertiary Hospital (Salvador / BA) diagnosed with acute coronary syndrome, in the period from 2011 to 2014. The patients were divided into three groups according to renal function and two groups according to clinical diagnosis.

Results: We identified six hundred seventy-four $(\mathrm{n}=674)$ individuals. Mean age was $69.6 \pm 12.4$ years and $50.7 \%(\mathrm{n}$ $=342$ ) were male. Regarding the clinical diagnosis, $49 \%$ of patients $(\mathrm{n}=331)$ were diagnosed with Unstable Angina and $50.9 \%(n=342)$ with Acute Myocardial Infarction. The average value of creatinine clearence rate was $63.2 \pm 29.3$ $\mathrm{ml} / \mathrm{min}(\mathrm{p}=0.001)$. Conclusion: The severe renal dysfucntion is an important prognostic factor for development of coronary artery disease and was associated with bad prognosis of patients with ACS. The variables DM, hypertension and dyslipidemia were often associated in theses patients.
\end{abstract}

Key words: Acute coronary syndrome; renal insufficiency; glomerular filtration rate. 


\section{Introduction}

Recently, cardiovascular diseases (CVD) are an important cause of mortality and disability in the World ${ }^{[1]}$, in Brazil ${ }^{[2,3]}$ and Bahia. ${ }^{[4]}$ Ischemic heart disease can develop multiple outcome. ${ }^{[5]}$ It can remain asymptomatic for a lifetime, can evolve for an Acute Coronary Syndrome (ACS), a chronic disease or sudden death. ${ }^{[2,6]}$

Epidemiological data demonstrated that SCA is an endemic disease. ${ }^{[7]}$ It is estimated that about 83 million adult United States population develop at least one type of cardiovascular disease. ${ }^{[5]}$ Of this total, about 15 million had coronary heart disease and in 2010 and of the total number of deaths recorded, $32 \%$ were cases related to cardiovascular disease ${ }^{[5,8]}$ On Brazilian scene, the figures reveal that the situations are similar. The prevalence of coronary artery disease in Brazil adult population is around 5 to $8 \%$ and about $32 \%$ of the population died due to cardiovascular problems. ${ }^{[4]}$

Kidney disease (KD) is a major systemic condition and constitutes common final pathway of many different diseases of the kidney and urinary tract, ${ }^{[9]}$ characterized by the renal failure function. ${ }^{[10]}$ Based on creatinine clearance values $(\mathrm{CrCl})$, renal function can be divided into mild impairment $(\mathrm{CrCl}>60 \mathrm{~mL} / \mathrm{dL})$, moderate $(\mathrm{CrCl} 30-60 \mathrm{ml} / \mathrm{dL})$ and severe $(\mathrm{CrCl}<30 \mathrm{~mL} / \mathrm{dL})$, with a subgroup represented dialytic patients dialíticos. ${ }^{[10]}$ Kidney disease is associated with risk factors that include: advanced age, male gender, hypertension, diabetes mellitus (DM), smoking and family history of CVD,${ }^{[5]}$ which are similar to the factors risk for ACS. [1] Thus it is not unusual that there is an association between ACS and kidney disease. The KD is associated with increasing mortality, since patients with mild to moderate degrees of renal impairment is showing worse prognosis of ACS when compared to those with preserver normal renal function. ${ }^{[1]}$

ACS is responsible for high costs in health care and the implementation of public and private politics that reduce these numbers depend on the understanding of studies to accurately reflect the strategy diagnoses and therapeutic. ${ }^{[12]}$ Knowledge about interventions that promote reduction in the incidence of CVD is a constant challenge. ${ }^{[13]}$ Risk factors for ischemic heart disease are not properly documented in Brazil ${ }^{[14]}$ and analysis of the clinical outcome of these patients is varied and there are few studies done on the subject.

\section{Methods}

\section{Study design and sample selection}

Consecutive patients admitted to the Emergency Ward and thereafter admitted to the Coronary Care Unit of the Hospital Português (Salvador, Bahia, Brazil) with a diagnosisof unstable angina (UA) or acute myocardial infarction (AMI) with ST segment elevation (SSE) and without SSE, from January 2011 to December 2014, participated in the study. We included those patients with chest pain or equivalent ischemic condition within 48 hours of admission and at least one of the three following characteristics: 1) ischemic electrocardiographic changes (T-wave inversion or ST segment depression), 2) serum markers of myocardial necrosis above the upper limit of normal, and/or 3) documentation of prior coronary artery disease.

We excluded patients with: ST-segment elevation $\geq 1$ $\mathrm{mm}$ in two or more leads on the admission ECG, normal coronary angiogram, hemodynamically significant primary valvular disease (mitral and aortic insufficiency or stenosis), hypertrophic cardiomyopathy, cancer, infectious diseases, autoimmune diseases and patients suffering from recent trauma or surgery.

This study was approved by the Ethics and Research Committee of Portuguese Hospital $\left(n^{\circ} 1074369\right)$. Patients information were recorded in electronic medical records. The identification information had been saved on the digital platform with the code numbers guaranteeing the anonymity of these.

\section{Statical analysis}

The baseline characteristics of the patients were summarized in four mutually exclusive groups of renal function and the types of diagnosis. For descriptive analysis, quantitative variables were represented by mean and standard deviation, where their distribution were normal, and represented by medians and interquartile ranges when the distribution was not normal. The definition of normality was made by graphical analysis and Shapiro-Wilk test. Categorical variables were represented by frequencies and percentages. In- 
clusion of variables have been carefully chosen, taking into account the number of monitoring events, to ensure parsimony of the final models. Statistical analysis was performed using the chi-square test, Test T student and Mann-Whitney test.

In order to identify which factors are associated with the combined events, we used the model of logistic regression. The variables with $\mathrm{p}<0.10$ were included in the model. Those that remained significant $(p<0.05)$ were considered independent for the occurrence of the outcome in question. Any p values $<0.05$ were considered statistically significant. Data were aggregated using the Statistical IBM software package for Social Sciences (SPSS ${ }^{\circledR}$, Chicago, IL, USA), version 20.0, and presented in numbers and informative graphics.

\section{Results}

Were identified six hundred seventy-four $(n=674)$ patients with ACS. The mean age was $69.6 \pm 12.4$ years and $50.7 \%(\mathrm{n}=342)$ were male. Regarding the clinical diagnosis, $49 \%$ of patients $(n=331)$ were diagnosed with UA and $50.9 \%(\mathrm{n}=342)$ with AMI. The mean (standard deviation) of the general creatinine clearance was $63.2 \pm 29.3(p=0.001)$. Forty-nine percent of the patients $(\mathrm{n}=330)$ had normal renal function, $39 \%(\mathrm{n}=266)$ moderate renal impairment and $12 \%$ $(\mathrm{n}=79)$ severe renal impairment. The analyzed comorbidities, $82.9 \%(\mathrm{p}=0.004)$ and $57.6 \%(\mathrm{p}=0.107)$ of the subjects had hypertension and hyperlipidemia, respectively, whereas only $10.1 \%(\mathrm{p}=0.859)$ had a family history of CAD.

Among the total sample, $3 \%(\mathrm{n}=20)$ died during follow-up in the CCU. These subjects had mostly age ( 80.2 $\pm 9.3 ; \mathrm{p}<0.001)$ and showed the lowest creatinine clearance values $(41.8 \pm 26.0, \mathrm{p}<0.005)$. The most common diagnosis in this population was AMI without ST elevation followed by myocardial infarction with ST elevation. Hypertension and DM showed, respectively, $75 \%$ and $45 \%$ $(p<0.05)$ among these patients. Demographic and clinical characteristics of patients are shown in Table 1.

Table 1. Demographic characteristics of ACS patients of Tertiary Hospital CCU, Salvador, Bahia - 2011 a 2014

\begin{tabular}{|c|c|c|c|c|}
\hline \multirow[t]{2}{*}{ Variable } & \multirow[t]{2}{*}{ General $(n=674)$} & \multicolumn{2}{|c|}{ Death } & \multirow[t]{2}{*}{$P$ value } \\
\hline & & No $(n=654)$ & Yes $(n=20)$ & \\
\hline Age (years) ${ }^{a}$ & $69,6 \pm 12,4$ & $69,3 \pm 12,3$ & $80,2 \pm 9,3$ & $<0,001$ \\
\hline Gender (M)a & $342(50,7)$ & $332(50,8)$ & $10(50)$ & 0,946 \\
\hline Hypertensio ${ }^{a}$ & $558(3)$ & $543(2,1)$ & $15(2,7)$ & 0,004 \\
\hline $\mathrm{DM}^{\mathrm{a}}$ & $255(3)$ & $246(1,8)$ & $9(3,5)$ & 0,001 \\
\hline Smoking $^{a}$ & $151(3)$ & $149(3)$ & $2(1,3)$ & 0,011 \\
\hline Dyslipidemia $^{a}$ & $388(3)$ & $380(2,8)$ & $8(2,1)$ & 0,107 \\
\hline CVD familiar historic ${ }^{a}$ & $68(3)$ & $66(2,4)$ & $2(2,9)$ & 0,859 \\
\hline Admission dyagnosis $^{c}$ & & & & 0,005 \\
\hline Unstbale Angina & $331(49,1)$ & $327(50,0)$ & $4(20,0)$ & \\
\hline AMI withou SSE & $264(39,2)$ & $253(38,7)$ & $11(55,0)$ & \\
\hline AMI with SSE & $79(11,7)$ & $74(11,7)$ & $5(25,0)$ & \\
\hline Creatinine clearance $(\mathrm{ml} / \mathrm{min})^{\mathrm{b}}$ & $63,2 \pm 29,3$ & $63,8 \pm 29,1$ & $41,8 \pm 26,0$ & 0,001 \\
\hline
\end{tabular}


Creatinine clearance values median $60 \mathrm{~mL} / \mathrm{min}$ (IQR $40-80$ ) and $35 \mathrm{ml} / \mathrm{min}$ (IQR 20-55) - $\mathrm{p}=0.005$ for the sample control and non-control, respectively - Figure 1. The lowest median $\mathrm{CrCl}$ values found was on the sample of patients diagnosed with SSE $>12$ hours and whose died $(20 \mathrm{ml} / \mathrm{min} ; \mathrm{p}<0.005)$ - Figure 3. Hypertension was present in $89.9 \%$ of individuals with severe KD and $80 \%$ mild KD $(\mathrm{p}=0.094)$. Dyslipidemia was the second most frequent comorbid affecting $57.6 \%(\mathrm{p}=$ $0.164)$. DM ranged from $32.9 \%$ in individuals with severe KD to $40.9 \%$ in those with mild KD $(p=0.250)$.

Independent predictors analysis of outcome occurring combined, the variables hypertension, diabetes mellitus, smoking and the degrees of renal function composed of losgistic regression model. The variables were selected for present value of $\mathrm{P}<0.10$ or clinical relevance well documented. Logistic regression analysis identified that the clearance rate of creatinine is a significant independent predictor of combined outcomes (OR: 3.44; 95\% CI: 1.827 to $6.493 ; \mathrm{p}<0.001)$ Table 2.

\section{Discussion}

Renal dysfunction (RD) and cardiovascular disease are strongly associated and currently the RD is being considered important risk factor for ACS (15). Kidney disease, as well as ACS are commonly associated with factors such as age, sex and other clinical conditions, and lifestyle habits. One should not, therefore, fail to consider the influence of these clinical conditions in the outcome of these patients.

Corroborating previous studies ${ }^{[2,6]}$ the prevalence of age was observed in the total sample, averaging 69.6 years $(p<0.001)$. The prevalence between the sex- es was not significant $(p=0.946)$. This finding goes against previous research findings as in Rio de Janeiro ${ }^{[3]}$ and Porto Alegre ${ }^{[2]}$ in which highlight the prevalence of males in their results. The clinical diagnosis was observed prevalence of AMI $(p=0.005)$ and between it the most common, regardless of evolution, was AMI without SSE, similar to that found in a study conducted in Brazil southern ${ }^{[2]}$ but differs from study conducted in cardiac emergency, in which achieved a $60 \%$ prevalence of patients with UI. ${ }^{[16]}$

In this study, the RD was considered a factor regardless of the outcome of patients, but moderate and severe disorders were associated with worse prognosis $(\mathrm{p}$ $=0.001)$. The values documented creatinine clearances revealed that the lowest rates were among patients who progressed to death. Thus, this study complements the findings of previous studies that have shown that severe $\mathrm{RD}$ is an independent predictor of cardiovascular events, ${ }^{[15,17]}$ suggesting increased $\mathrm{RD}$ frequency in mor-

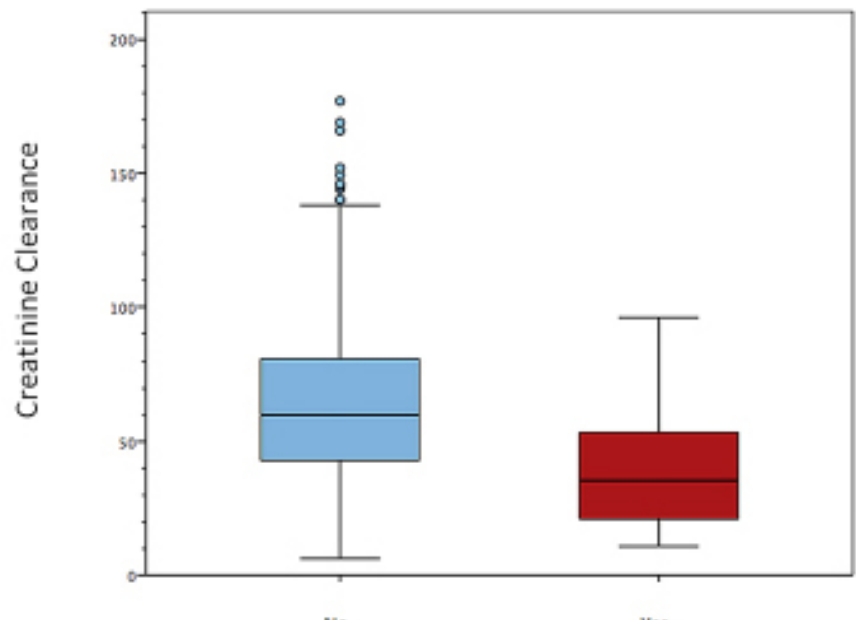

Figure 1. Death

Table 2. Logistic regressino for outcome combined events. Tertiary Hospital, Salvador, Bahia, 2011 a 2014.

\begin{tabular}{|l|c|c|c|c|}
\hline \multicolumn{1}{|c|}{ Variable } & OR & \multicolumn{2}{|c|}{ I.C.95\% } & P value \\
\hline Hypertension & 0,56 & 0,19 & 1,6 & 0,270 \\
\hline DM & 1,74 & 0,7 & 4,350 & 0,233 \\
\hline Smoking & 0,19 & 0,06 & 0,59 & 0,004 \\
\hline CICr & 3,44 & 1,83 & 6,493 & $<0,001$ \\
\hline DM: Diabete Mellitus; CICr: creatinine clearance; OR: odds ratio & & \\
\hline
\end{tabular}


bidity and mortality of patients with $\operatorname{ACS}^{[15,17,18,25]}$ and therefore, patients with renal impairment severe usually have worse prognosis. ${ }^{[19]}$ Patients who progressed to death had increased kidney damage, among themselves, and between the control sample was greater frequency of normal kidney function.

It is believed that some factors that compromise renal function may contribute to adverse outcomes in ACS patients. Among these factors are included insulin resistance, extracellular changes, oxidative stress and endotelial dysfunction, ${ }^{[18]}$ so the RD is directly or indirectly involved in the development of hypertension, dyslipidemia, and neuroendocrine disorders important contributors to the advancement of acute coronary disease. ${ }^{[15]}$ Analysis data showed that among the risk factors highlighted the massive presence of hypertension, which affected about $90 \%(p=0.004)$ of the sample, being prevalent in the two study groups. Then, it was noted that dyslipidemia was also quite common such. DM, however, was present in most patients who died and a little less in the control group. Smoking was not so frequent in the study because most of the individuals denied the habit, but, however, the rate was similar in both groups. Another clinical condition was researched family history of CVD who remained not significant because the vast majority of patients were not aware of this information.

This study demonstrates the hypertension as the most prevalent risk factor for ACS. In the 90s, the Framingham, ${ }^{[20]}$ study's found the prevalence of hypertension were as follows: patients without disease $38 \%$; patients who had sudden death from heart disease $63 \%$; and patients with non-sudden death from heart disease
$79 \%$. Similarly, the study FRICAS case-control showed an association with hypertension of $53.4 \%$ among cases and $20,8 \%$ of the controls $(\mathrm{P}=0.000){ }^{[29]}$ These results confirm the importance of hypertension as a risk factor for the occurrence of ACS. ${ }^{[1]}$

In earlier descriptive and retrospective studies, in Brazil south ${ }^{[1]}$ such as in Bahia, ${ }^{[22]} \mathrm{DM}$ was present in about $40 \%$ of patients. In the present study, DM was recorded at $37.8 \%(p=0.001)$ of patients going against the expectations.

In this study, smoking was found in $22.4 \%$ of patients $(p=0.011)$, since about $74 \%$ of patients denied the use of tobacco. This result was not expected since previous studies, such as Interheart it demonstrated that smoking, with a consumption of one to five cigarettes / day increases the risk of AMI in $40 \%,{ }^{[23]}$ similar to the study data made in Porto Alegre. ${ }^{[1]}$

The limitations on the present study relate to observational and retrospective nature of research with interpretation of clinical data. In addition, this study was a single center; so your results may not be fully extended to other populations.

It is essential to understand that many patients with ACS are also carriers of RD and the association of these two conditions can increase the mortality rate. Moreover, despite universal issues it is possible that regional variations related to demographic conditions, can influence differently, so varying from place to place. Thus, the analysis of the importance of complications in patients with ACS, allows investigation and treatment strategies are applied correctly. 


\section{References}

1. Lemos KF. Prevalência de fatores de risco para síndrome coronariana aguda em pacientes atendidos em uma emergência. 2010;31(1):129-35.

2. Magee RF, Freitas G De, Borges B, Antonio G, Daher G, Macedo RG, et al. Revista de Medicina e Saúde de Brasília Síndrome Coronariana Aguda: uma revisão. Rev Med Saude Brasilia 2012; 1(3):174-89

3. State RDJ, Helena L, Salis A, Monteiro A, Dias DC, Guerra C, et al. Síndrome Coronariana Aguda: morbimortalidade e prática clínica em pacientes do município de Niterói (RJ). 2007;20(5):360-71.

4. Piegas LS, Avezum A, Guimarães HP, et al. Acute coronary syndrome behavior: results of a Brazilian registry. Arq Bras Cardiol;100(6):502-10.

5. Go AS, Mozaffarian D, Roger VL, Benjamin EJ, et al. Heart disease and stroke statistics-2014 update: a report from the American Heart Association.

6. Minuzzo L, Pereira MP, Teresa M, Castillo C, et al. Acute Coronary Syndrome Registry at a Cardiology Emergency Center. 2005;544-9.

7. Martins Romêo Neto L, Martins Romêo Filho L. Determinantes da Mortalidade da Síndrome Coronariana Aguda sem Supradesnivelamento do Segmento ST. Revista Brasileira de Cardiologia. 2012;25(6):471-478.

8. Mass B, Diet H, Plasma BP, Health N. Prevalence ( unadjusted ) estimates for poor, intermediate and ideal cardiovascular health, US children aged 12-19 years Age-standardized prevalence for poor, intermediate and ideal cardiovascular health, US adults $\geq 20$ years of age. 2013;2009-10.

9. Paulo EDS, Cássia R De, Mendonça H, Allana G, Alves S, Ribeiro DF, et al. WCN 2007 / Nursing Meeting Caracterização e etiologia da insuficiência renal crônica em unidade de nefrologia do interior do Estado de São Paulo. 2008;21:207-11.

10. Nogueira, C. S. \& Oliveira, C. R. D. Disfunção renal: Definição e diagnóstico. Medicina Perioperatória. São Paulo: SAESP, 2006/2007. Cap.64, p.87-125.

11. Serrano Jr C, Cecott H, Uehara T, Leite R, Carvalho da Costa M. Doença coronária aguda e insuficiência renal crônica. Revista Brasileira de Hipertensão. 2008;15(3):147-151.

12. Nicolau J, Franken M, Lotufo P, Carvalho A, Marin Neto J, Lima F et al. Utilização de terapêuticas comprovadamente úteis no tratamento da coronariopatia aguda: comparação entre diferentes regiões brasileiras. Análise do Registro Brasileiro de Síndromes Coronarianas Agudas (BRACE - Brazilian Registry on Acute Coronary Syndromes). Arq Bras Cardiol. 2012;98(4):282-289

13. Mattos L, Berwanger O, Santos E, Reis H, Romano E, Petriz J et al. Desfechos clínicos aos 30 dias do registro brasileiro das síndromes coronárias agudas (ACCEPT). Arq Bras Cardiol. 2013;100(1):6-13.

14. Piegas LS, Avezum A, Pereira JCR, Neto JMR, Hoepfner C, Farran J a, et al. Risk factors for myocardial infarction in Brazil. Am Heart J [Internet]. 2003 Aug;146(2):331-8.

15. Liu Y, Gao L, Xue Q, Yan M, Chen P, Wang Y et al. Impact of renal dysfunction on long-term outcomes of elderly patients with acute coronary syndrome: a longitudinal, prospective observational study. BMC Nephrol. 2014;15(1).

16. Santos ES, Minuzzo L, Pereira MP, Castillo MTC, Pa- lácio MAG, Ramos RF, et al. Registro de síndrome coronariana aguda em um centro de emergências em cardiologia. Arq Bras Cardiol. 2006;87(5):597-602.

17. Orvin K, Eisen A, Goldenberg I, Farkash A, Shlomo N, GevrielovYusim $\mathrm{N}$ et al. The proxy of renal function that most accurately predicts short- and long-term outcome after acute coronary syndrome. American Heart Journal. 2015;169(5):702-712.e3.

18. Rozenbaum Z, Leader A, Neuman Y, et al. Prevalence and Significance of Unrecognized Renal Dysfunction in Patients with Acute Coronary Syndrome. The American Journal of Medicine. 2016;129(2):187-194.

19. Anavekar N, McMurray J, Velazquez E. Relation between renal dysfunction and cardiovascular outcomes after myocardial infarction. ACC Current Journal Review. 2004;13(12):9-10

20. Wilson PW. Established rik factors and coronary artery disease: the Framingham Study. Am J Hypertens 7: 7S:-12S, 1994

21. Silva MAD, Souza AGMR, Schargodsky H. Fatores de risco para infarto do miocárdio no Brasil: estudo FRICAS. Arq Bras Cardiol. 1998;71(5):667-75.

22. Pinheiro MGV, Rabelo Jr A, Jesus RS, Nascimento LC, Costa UMM Síndromes coronarianas agudas na ausência de doença arterial coronariana significati- va. Arq Bras Cardiol. 2005;84(1):24-8.

23. Yusuf S, Hawken S, Ôunpuu S, Dans T, Avezum A, Lanas F, et al. Effect of potentially modifiable risk factors associated with myocardial infarction in 52 countries (the INTERHEART study): case-control study. Lancet. 2004;364:937-52.

Received: 05/10/2016

Accepted: 06/12/2016

Published: 20/12/2016

Disclosure and conflicts of interest:

Conflicts of interest were not reported.

\section{Corresponding author:}

Maria Eduarda Seabra O. Halmeira

Mail: meduardaseabra@hotmail.com 